
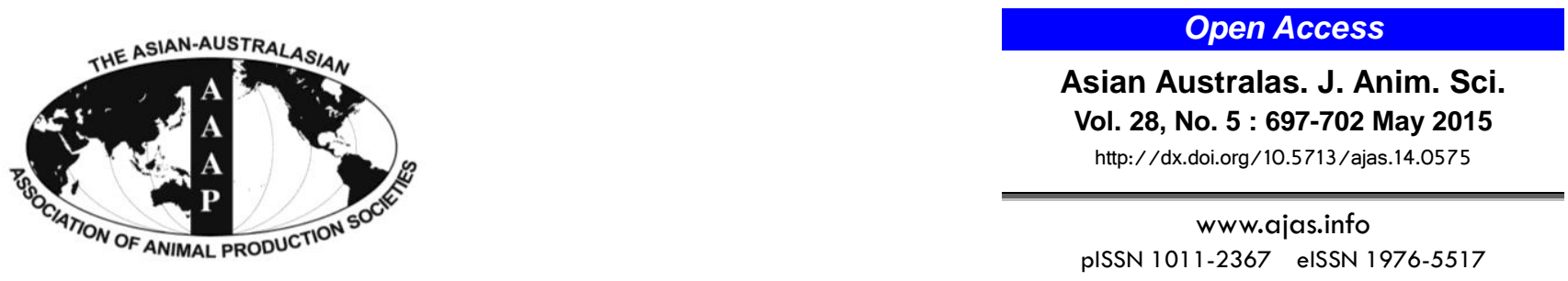

\title{
Molecular Characterization and Expression Analysis of the Peroxisome Proliferator Activated Receptor Delta (PPARס) Gene before and after Exercise in Horse
}

\author{
Hyun-Woo Cho ${ }^{\text {a }}$, Sangsu Shin ${ }^{1, a}$, Jeong-Woong Park, Jae-Young Choi, Nam-Young Kim ${ }^{2}$, \\ Woon-Kyu Lee ${ }^{3}$, Hak-Kyo Lee ${ }^{4}$, Ki-Duk Song ${ }^{4}$,*, and Byung-Wook Cho* \\ Department of Animal Science, College of Life Sciences, Pusan National University, Miryang 627-702, Korea
}

\begin{abstract}
While athletic abilities such as speed, endurance and recovery are important in the horse, genes related to these abilities have not been extensively investigated. Here, we characterized the horse peroxisome proliferator-activated receptor delta $(P P A R \delta)$ gene and analyzed the expression of PPAR $\delta$ during exercise. PPAR $\delta$ is a known regulator of $\beta$-oxidation, muscle fiber transformation, and running endurance. Through evolutionary analysis using the synonymous and non-synonymous mutation ratio, it was revealed that positive selection occurred in the horse PPAR $\delta$ gene. Two important domains related to nuclear hormone receptors, $\mathrm{C} 4$ zinc finger and ligand binding domain, were also found to be conserved well in horse PPAR $\delta$. Horse PPAR $\delta$ was expressed ubiquitously in many tissues, but the expression level was various depending on the tissues. In the skeletal muscle, PPAR $\delta$ increased about 2.5 folds after 30 min of exercise. Unlike in muscle, the increase of PPAR $\delta$ expression was observed at 60 min but not 30 min of exercise in leukocytes. This finding might be useful for testing the endurance of horse using blood samples. Conclusively, the horse PPAR $\delta$ gene is evolutionarily conserved well and can be used as a biomarker of endurance in horse. (Key Words: Horse, Peroxisome Proliferator-activated Receptor Delta, Exercise, Endurance)
\end{abstract}

\section{INTRODUCTION}

Many economic traits including speed, robustness, and endurance of racing horses are related to exercise. Previously, whole transcriptome analysis using RNAsequencing in six thoroughbred horses before and after

\footnotetext{
* Corresponding Authors: Ki-Duk Song. Tel: +82-31-670-5656, E-mail: kiduk.song@gmail.com / Byung-Wook Cho. Tel: +82-55350-5515, Fax: +82-55-350-5519, E-mail: bwcho@pusan.ac.kr

${ }^{1}$ Life and Industry Convergence Research Institute, College of Natural Resource and Life Science, Pusan National University, Miryang 627-706, Korea.

${ }^{2}$ Subtropical Animal Experiment Station, National Institute of Animal Science, RDA, Jeju 690-150, Korea.

${ }^{3}$ College of Medicine, Inha University, Incheon 400-712, Korea.

${ }^{4}$ Genomic Informatics Center, HanKyong National University, Anseong 456-749, Korea.

${ }^{a}$ These authors contributed equally to this work.

Submitted Jul. 29, 2014; Revised Oct. 1, 2014; Accepted Oct. 27, 2014
}

exercise was performed to identify exercise-related genes (Park et al., 2012). Differentially expressed gene analysis of skeletal muscle and blood using RNA-sequencing of selected genes regarded as associated with economically important traits of horses has become an interest for the purposes of selection and improvement.

Peroxisome proliferator-activated receptors $(P P A R)$ are members of the nuclear receptor superfamily and was first identified in xenopus (Krey et al., 1993). PPARs can be activated and cooperate with thyroid hormone and retinoid $\mathrm{X}$ receptors by the formation of a heterodimer complex for transcriptional regulation of target genes (Wahli et al., 1995). PPARs play essential roles in the regulation of cellular differentiation, development, metabolism (carbohydrate, lipid, protein), and tumorigenesis of higher organisms (Berger and Moller, 2002; Belfiore et al., 2009). Among the PPARs, PPAR $\delta$ has an important role in fat metabolism in muscle; in knockout mice studies, it has been shown that it activates oxidation of fatty acid in muscle 
while increases conversion of glucose to fatty acid in liver (Lee et al., 2006). The overexpression of PPAR $\delta$ resulted in an increased oxidative metabolism and hyperplasia causing the change of fiber composition in mouse muscle (Luquet et al., 2003). Together with its metabolic role in muscle, $P P A R \delta$ acts as an important regulator of satellite cell proliferation and muscle regeneration (Angione et al., 2011).

According to previous studies, expression of PPAR $\delta$ mRNA and protein is increased in the skeletal muscle after endurance exercise (Luquet et al., 2003; Mahoney et al., 2005). PPAR's expression in skeletal muscle is related to the late induction of exercise-induced responses during endurance training, such as increased oxidative capacity of type I muscle fibers and mitochondrial biogenesis (Wang et al., 2004). The overexpression of PPAR $\delta$ in mouse skeletal muscle induces the up-regulation of gene expression related to slow fiber contractile proteins, mitochondrial biogenesis, and $\beta$-oxidation. Therefore, the rapid and regulated changes of PPAR $\delta$ expression could improve physical performance.

Despite extensive and numerous studies on the function and expression of the PPAR $\delta$ gene in various species, it has not been researched in horses. The objective of this study was to characterize the horse PPAR $\delta$ gene at the molecular level by performing bioinformatics and the realtime polymerase chain reaction (RT-PCR) analysis, and to investigate the transcriptional regulation of PPAR $\delta$ gene after exercise and the possibility of $P P A R \delta$ as a biomarker.

\section{MATERIALS AND METHODS}

\section{Bioinformatic analysis of horse peroxisome proliferator- activated receptor delta gene}

The coding DNA and amino acid sequences of PPAR $\delta$ of various species (horse, human, chimpanzee, mouse, rat, cow, pig, chicken, dog, and cat) were retrieved from Ensembl (http://www.ensembl.org/). The amino acid sequences were aligned using ClustalW in the BioEdit software. The protein domains were predicted by using the SMART domain search program (http://smart.emblheidelberg.de/). Phylogenetic analysis data was obtained by using the Neighbor-Joining method (Saitou and Nei, 1987) in MEGA software (Tamura et al., 2011). The parameters were as follows: pairwise-deletion, 1000 bootstrap replications, and Kimura 2. Pairwise deletion was chosen to retain all such sites initially, excluding them as necessary in the pairwise distance estimation. The group within tree was used for 1000 bootstrap replications to derive the reliability value. Substitutions of nucleotides were obtained by using the Kimura 2-parameter model. We also showed synonymous substitutions per site (Ks) and nonsynonymous substitutions per site $(\mathrm{Ka})$ in $P P A R \delta$ gene for individual variation.

\section{Horse blood and tissue samples}

Blood and muscle samples were collected from three thoroughbred horses, which were 2 to 4 year-old geldings and maintained at Ham-an Racing Horse Resort \& Training Center. Samples were collected before and after $30 \mathrm{~min}$ and $60 \mathrm{~min}$ of trotting. Exercise was performed about $13 \mathrm{~km} / \mathrm{h}$ of speed on a treadmill. The National Institute of Subtropical Agriculture, Rural Development Administration, Republic of Korea, provided three Jeju horses which were used for tissue sampling. Skeletal muscle, kidney, thyroid, lung, appendix, colon, spinal cord and heart tissues were kept in a liquid nitrogen tank until RNA extraction. Animal care and sample collection were conducted in accordance with protocols approved by the Institutional Animal Care and Use Committee of the Pusan National University (PNU-2014-0644 and PNU-2014-0645).

\section{RNA extraction and cDNA synthesis}

Trizol reagent (Invitrogen, Carlsbad, CA, USA) was used to extract total RNA from tissue samples and leukocytes according to the manufacturer's manual. In order to prevent contamination of genomic DNA, all RNA samples were treated with RNase-free DNase (Qiagen, Venlo, Netherlands). Next, the RNA samples were quantified by using a NanoDrop ND-1000 Spectrophotometer (Thermo Fisher Scientific Inc., Waltham, MA, USA). The cDNA was synthesized from the each RNA sample by moloney-murine leukemia virus reverse transcriptase (Promega, Madison, WI, USA) in a reaction containing oligo-dT primers and RNase inhibitor (Promega, USA) for 4 hours incubating at $37^{\circ} \mathrm{C}$.

\section{Real time-quantitative polymerase chain reaction analysis}

Firstly, PCR was conducted to verify the removal of genomic DNA and the synthesis of cDNA. The PPAR $\delta$ and glyceraldehyde 3-phosphate dehydrogenase (GAPDH). primer sets for PCR were designed by using the PRIMER3 software (http://frodo.wi.mit.edu/primer3/). The sequences of PPAR $\delta$ primers were 5'- AGC AAC CTC TTC CTC AAC GA-3' for forward primer and 5'- GAG GCT GCG TAG GAA CTC AC-3' for reverse primer. The PCR product size of PPAR $\delta$ was expected to be $150 \mathrm{bp}$. The PCR conditions consisted of an initial step of $94^{\circ} \mathrm{C}$ for $10 \mathrm{~min}$, 35 cycles of $94^{\circ} \mathrm{C}$ for $30 \mathrm{~s}, 60^{\circ} \mathrm{C}$ for $30 \mathrm{~s}, 72^{\circ} \mathrm{C}$ for $30 \mathrm{~s}$, and a final step of $72^{\circ} \mathrm{C}$ for $10 \mathrm{~min}$. The PCR products were analyzed by electrophoresis on a $2.0 \%$ Seakem LE agarose gel.

To quantify the PPAR $\delta$ gene in horse tissues and leukocytes, RT-quantitative polymerase chain reaction (qPCR) was conducted by using CFX-96 real-time PCR (BioRad, Hercules, CA, USA). Each reaction was executed in $25 \mu \mathrm{L}$ of a total volume containing $14 \mu \mathrm{L}$ of SYBR green 
master mix, $2 \mu \mathrm{L}$ of forward primer $(5 \mathrm{pmol}), 2 \mu \mathrm{L}$ of reverse primer $(5 \mathrm{pmol}), 5 \mu \mathrm{L}$ of distilled water, and $2 \mu \mathrm{L}$ of the cDNA $(50 \mathrm{ng} / \mu \mathrm{L})$. The PCR conditions were as follows: a pre-denaturation step at $94^{\circ} \mathrm{C}$ for $3 \mathrm{~min}, 39$ cycles at $94^{\circ} \mathrm{C}$ for $10 \mathrm{~s}, 60^{\circ} \mathrm{C}$ for $30 \mathrm{~s}$, and $72^{\circ} \mathrm{C}$ for $30 \mathrm{~s}$, followed by a final step at $72^{\circ} \mathrm{C}$ for $10 \mathrm{~min}$. Dissociation was accomplished in conditions where temperature increased from $60^{\circ} \mathrm{C}$ to $95^{\circ} \mathrm{C}$ for over 25 min (linear increase of $0.5^{\circ} \mathrm{C}$ ). All samples were measured in triplicate to ensure reproducibility, and the expression levels were calculated from $\mathrm{Ct}$ value by using the $2^{-\triangle \Delta \mathrm{Ct}}$ method (Livak and Schmittgen, 2001). The GAPDH gene was used for reference.

\section{Statistical analysis of gene expression}

The significance $(\mathrm{p}<0.05)$ of data was determined using Student's t-test or analysis of variance method. The difference among each value was determined by Tukey's test with alpha $=0.05$. All data values are presented as mean \pm standard error of mean.

\section{RESULTS AND DISCUSSION}

The horse PPAR $\delta$ gene consisted of eight exons with a total length of 1,644 bp. The translation of PPAR $\delta$ starts in the third exon and stops at the last exon. In comparing the nucleotide sequences in various species (human, chimpanzee, mouse, rat, cow, pig, chicken, dog, cat), the synonymous substitution (Ks) ranged from 0.363 to 1.330 , whereas the non-synonymous substitution $(\mathrm{Ka})$ ranged from 0.407 to 1.553 in horse (Table 1$)$. It is of note that the lowest (0.407) and highest (1.553) differences of Ka of horse PPAR $\delta$ were obtained when horse compared with cat and horse compared with mouse respectively. Human and chimpanzee are of similar sequence and/or amino acid, showing the lowest Ks value (0.018). The average Ka value was 1.056 and that of $\mathrm{Ks}$ was 0.914 , resulting to a $\mathrm{Ka} / \mathrm{Ks}$ ratio greater than 1 . This indicates that non-synonymous substitutions occurred faster than synonymous substitutions. These results are based on the assumption that the proteincoding regions in the human genome undergo positive selection during evolution (Bustamante et al., 2005). Results indicate that positive selection occurred in the PPAR $\delta$ genes during evolution in horses. This ratio also suggests possible evolution of the PPAR $\delta$ gene in various species.

To characterize horse PPAR $\delta$ protein, amino acid sequences of PPAR $\delta$ from various species were aligned and analyzed. The PPAR $\delta$ amino acid sequences are highly conserved between the species except for the N-terminal of the sequence (Figure 1A). In domain search using the SMART program, it was revealed that horse PPAR $\delta$ protein has two highly conserved domains, $\mathrm{C} 4$ zinc finger and ligand binding domains of nuclear hormone receptors. In a phylogenetic analysis with the Neighbor-Joining method, horse PPAR $\delta$ is clustered in the same clade with dog and chicken while having a large genetic distance from mouse and rat (Figure 1B).

Next, we performed RT-PCR analysis using eight different tissues from three horses to examine the gene expression pattern. All horse tissues expressed the PPAR $\delta$ gene ubiquitously, and $P P A R \delta$ was highly expressed in thyroid and lung while relatively low in skeletal muscle (Figure 2). It is of note that PPAR $\delta$ was highly expressed in thyroid cells unlike other PPAR genes such as PPAR $\alpha$ and PPARy (Bookout et al., 2006). High expression of the $P P A R \delta$ in thyroid and lung also corresponds to a previous expression study in xenopus (Krey et al., 1993). In human, the expression of $P P A R \delta$ in primary thyroid cells was induced by serum, thyroid-stimulation hormone, and cyclic AMP (3'-5'-cyclic adenosine). PPAR $\delta$ is up-regulated in human thyroid tumors and induces cell proliferation through the cyclin E1. In this sense, increased expression of PPAR $\delta$ and $\mathrm{Ki}-67$ is known as an in situ proliferation marker of benign and malignant human thyroid tumors

Table 1. Synonymous (Ks) and non-synonymous (Ka) substitutions per site in the $P P A R \delta$ gene of various species

\begin{tabular}{|c|c|c|c|c|c|c|c|c|c|c|}
\hline \multirow{2}{*}{ Ks } & \multicolumn{10}{|c|}{$\mathrm{Ka}$} \\
\hline & Horse & Human & Chimpanzee & Mouse & Rat & Cow & Pig & Chicken & Dog & Cat \\
\hline Horse & - & 0.859 & 0.855 & 1.553 & 1.521 & 0.507 & 0.897 & 1.452 & 0.439 & 0.407 \\
\hline Human & 0.766 & - & 0.021 & 1.508 & 1.471 & 0.484 & 0.987 & 1.620 & 0.892 & 0.686 \\
\hline Chimpanzee & 0.769 & 0.018 & - & 1.513 & 1.488 & 0.480 & 0.993 & 1.627 & 0.877 & 0.681 \\
\hline Mouse & 1.330 & 1.266 & 1.262 & - & 0.258 & 1.020 & 1.555 & 1.522 & 1.565 & 1.174 \\
\hline Rat & 1.292 & 1.245 & 1.245 & 0.246 & - & 0.957 & 1.505 & 1.537 & 1.514 & 1.062 \\
\hline Cow & 0.500 & 0.445 & 0.443 & 0.905 & 0.847 & - & 0.534 & 1.577 & 0.507 & 0.622 \\
\hline Pig & 0.798 & 0.874 & 0.875 & 1.325 & 1.271 & 0.512 & - & 1.61 & 1.024 & 0.692 \\
\hline Chicken & 1.245 & 1.400 & 1.400 & 1.280 & 1.334 & 1.331 & 1.253 & - & 1.606 & 1.447 \\
\hline Dog & 0.407 & 0.795 & 0.783 & 1.291 & 1.244 & 0.491 & 0.889 & 1.338 & - & 0.433 \\
\hline Cat & 0.363 & 0.593 & 0.597 & 1.038 & 0.964 & 0.622 & 0.593 & 1.252 & 0.394 & - \\
\hline
\end{tabular}

PPAR $\delta$, peroxisome proliferator-activated receptor delta.

The numbers displayed in the table are the Ka and Ks substitutions between the corresponding species. 
(A)

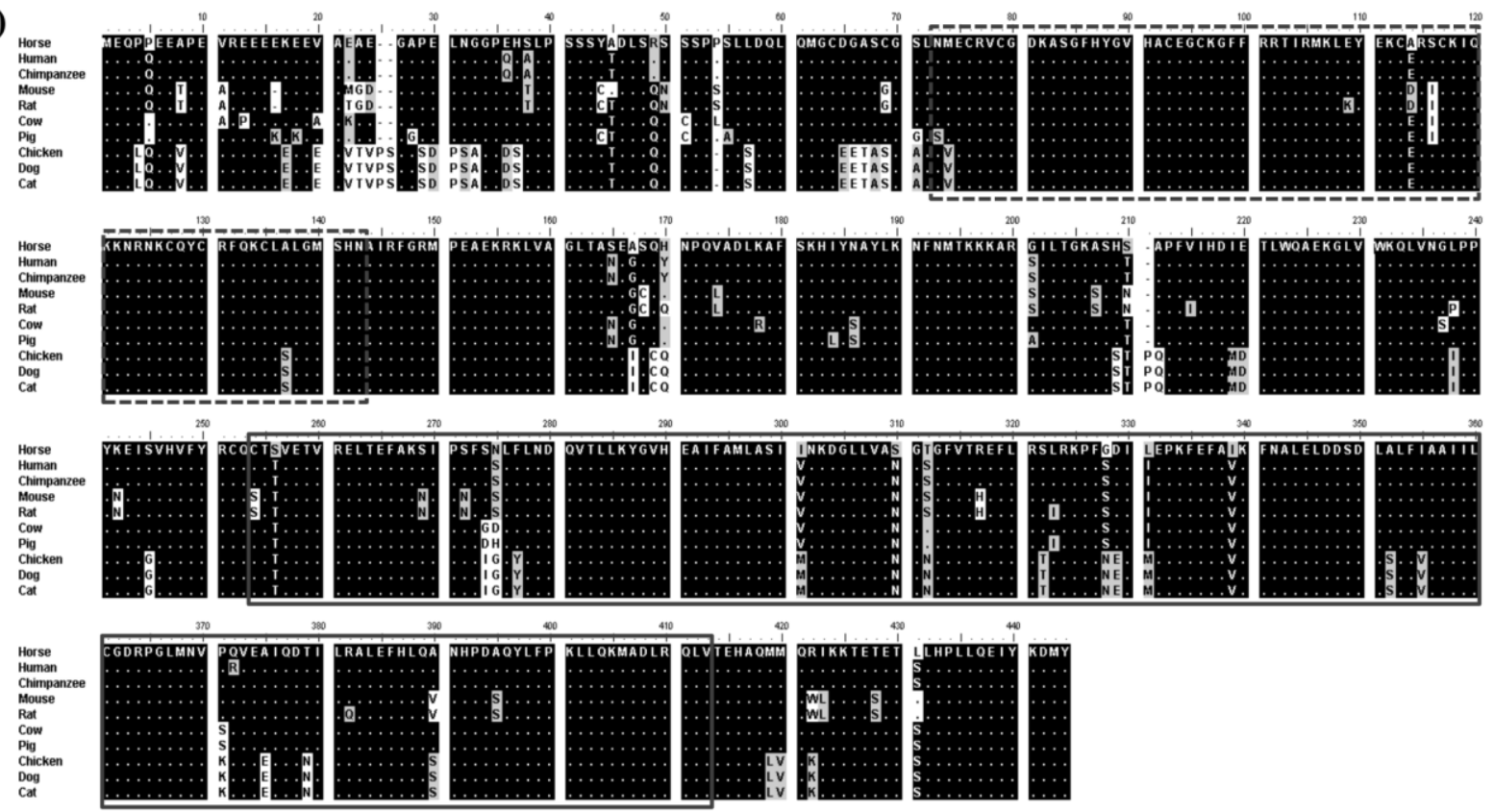

(B)

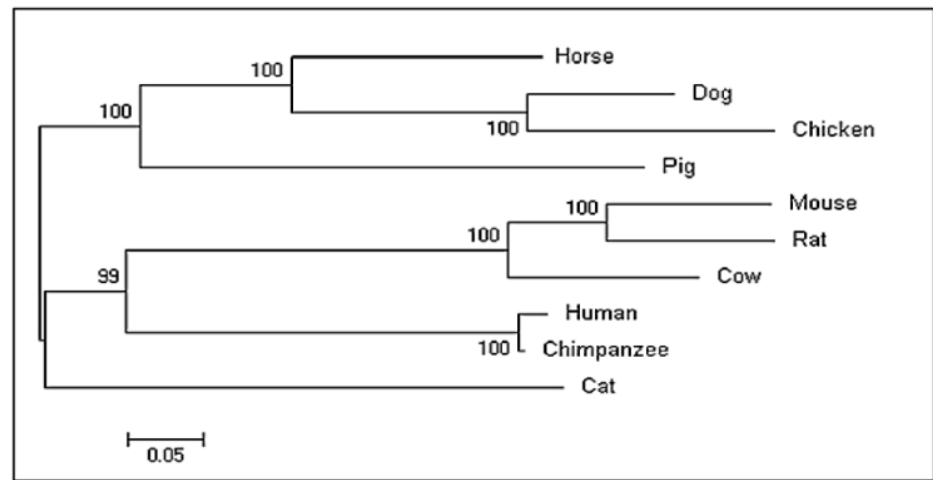

Figure 1. Analysis of horse PPAR $\delta$ amino acid sequences. (A) Comparison of amino acid sequences of horse PPAR $\delta$ in various species. In SMART domain prediction, it is revealed that $\mathrm{C} 4$ zinc finger (dashed box) and ligand binding (solid box) domains of nuclear hormone receptors were conserved in horse PPAR $\delta$. (B) Phylogenetic tree of PPAR $\delta$ in various species. PPAR $\delta$, peroxisome proliferator-activated receptor delta.

(Zeng et al., 2008), where the mean expression of native $P P A R \delta$ was increased by 2 -fold to 5 -fold and correlated with that of the in situ proliferation marker Ki67 in six different classes of benign and malignant human thyroid tumors.

To identify the relation between exercise and PPAR $\delta$ gene expression levels, the expression pattern of the gene was analyzed in skeletal muscle and leukocytes of horse. In skeletal muscle, PPAR $\delta$ was highly expressed about 2.5 fold at $30 \mathrm{~min}$ of exercise (Figure $3 \mathrm{~A}, \mathrm{p}<0.001$ ). In leukocytes, expression levels of PPAR $\delta$ were analyzed by RT-qPCR with the samples obtained before and after $30 \mathrm{~min}$ and 60 min of exercise (Figure 3B). Unlike skeletal muscle, which showed higher expression at $30 \mathrm{~min}$ of exercise, the expression of PPAR $\delta$ increased slowly and was significantly higher at $60 \mathrm{~min}$ of exercise in leukocytes. It is well known that endurance exercise increases expression of PPAR $\delta$ gene in the muscle of mouse and human (Luquet et al., 2003; Wang et al., 2004; Mahoney et al., 2005). This expression pattern of PPAR $\delta$ was also observed in horse muscle and even in the leukocytes although it took a longer time than in muscle. The increase of PPAR $\delta$ expression in horse muscle might induce the oxidative metabolism to supply the energy required for endurance exercise. As the leukocytes are relatively feasible method of collecting samples from the living horse, analysis of PPAR $\delta$ expression in leukocytes may be a useful tool for indirectly scoring the muscle fatigue.

\section{CONCLUSION}

In conclusion, the horse PPAR $\delta$ gene is well conserved evolutionarily and has functional domains found in other animals. The expression of PPAR $\delta$ gene is regulated by 
(A)

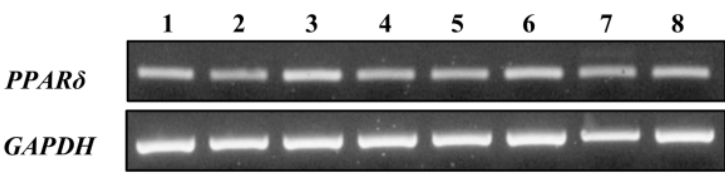

(B)

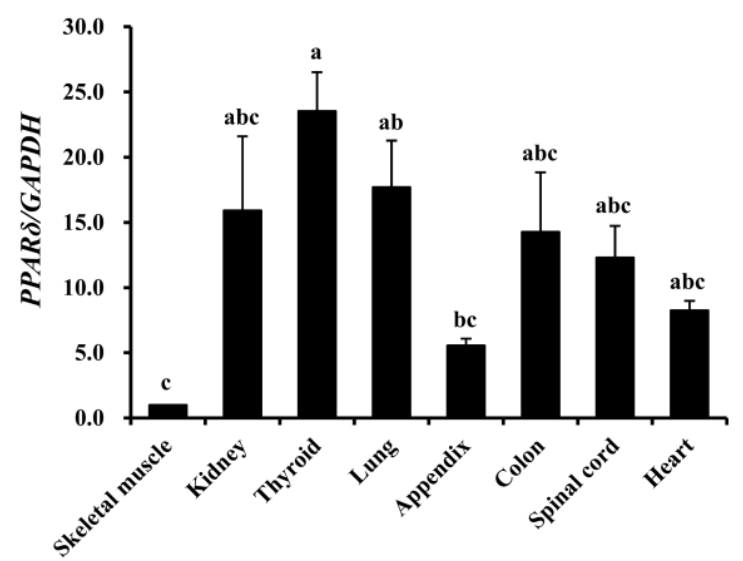

Tissues

Figure 2. Analysis of horse PPAR $\delta$ expression in various tissues of Jeju horse. (A) Expression of horse PPAR $\delta$ gene in various tissues. 1: skeletal muscle, 2: kidney, 3: thyroid, 4: lung, 5: appendix, 6: colon, 7: spinal cord, and 8: heart. The bands are saturated by running the polymerase chain reaction for 35 cycles. (B) Determination of expression levels of horse PPAR $\delta$ in horse tissues. Expression value was calculated using the $2^{-\Delta \Delta \mathrm{Ct}}$ method. The values are presented by mean \pm standard error of mean. The expression levels of the gene were various in tissues $(\mathrm{n}=3, \mathrm{p}<0.01)$. The difference of each value was determined by Tukey's test and the bars containing same letter on the top are not significantly different among them (alpha $=0.05$ ). GAPDH was used for normalization. PPAR , peroxisome proliferatoractivated receptor delta; $G A P D H$, glyceraldehyde 3-phosphate dehydrogenase.

(A)

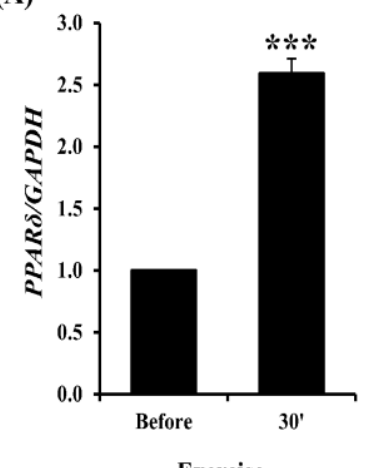

(B)

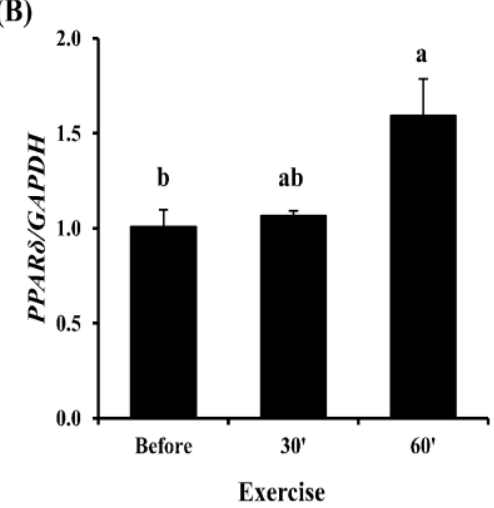

Figure 3. Analysis of $P P A R \delta$ expression before and after exercise in skeletal muscle and leukocytes. (A) Expression level of PPAR $\delta$ before and at $30 \mathrm{~min}$ after exercise in horse skeletal muscle. The expression of PPAR $\delta$ increased about 2.5 fold at 30 min of exercise in skeletal muscle $(\mathrm{n}=5)$. $* * *$ means $\mathrm{p}<0.001$. (B) Expression analysis of horse PPAR $\delta$ before and after exercise in leukocytes. Expression value was calculated using the $2^{-\triangle \Delta \mathrm{Ct}}$ method. The values are presented by mean \pm standard error of mean. The expression levels of $P P A R \delta$ was significantly higher after $60 \mathrm{~min}$ of exercise than before exercise $(\mathrm{n}=3, \mathrm{p}<0.05)$. The difference of each value was determined by Tukey's test and the bars containing same letter on the top are not significantly different (alpha $=0.05$ ). GAPDH was used for normalization. PPAR $\delta$, peroxisome proliferator-activated receptor delta; GAPDH, glyceraldehyde 3-phosphate dehydrogenase.

endurance exercise in muscle and leukocytes, and this gene could be a useful biomarker to measure endurance and fatigue. In further studies, the analysis of gene expression related to oxidation, mitochondrial biogenesis, and enhancement of physical performance by PPAR $\delta$ after exercise might be useful for understanding the relationship between PPAR $\delta$ and athletic ability in horse.

\section{ACKNOWLEDGMENTS}

This work was supported by a grant from the Next-
Generation BioGreen 21 Program (No. PJ011044 and PJ011173), Rural Development Administration, Republic of Korea.

\section{REFERENCES}

Angione, A. R., C. Jiang, D. Pan, Y. X. Wang, and S. Kuang. 2011. PPARdelta regulates satellite cell proliferation and skeletal muscle regeneration. Skelet. Muscle 1:33.

Belfiore, A., M. Genua, and R. Malaguarnera. 2009. PPAR-gamma agonists and their effects on IGF-I receptor signaling: Implications for cancer. PPAR Res. 2009:ID830501. 
Berger, J. and D. E. Moller. 2002. The mechanisms of action of PPARs. Annu. Rev. Med. 53:409-435.

Bookout, A. L., Y. Jeong, M. Downes, R. T. Yu, R. M. Evans, and D. J. Mangelsdorf. 2006. Anatomical profiling of nuclear receptor expression reveals a hierarchical transcriptional network. Cell 126:789-799.

Bustamante, C. D., A. Fledel-Alon, S. Williamson, R. Nielsen, M. T. Hubisz, S. Glanowski, D. M. Tanenbaum, T. J. White, J. J. Sninsky, R. D. Hernandez, D. Civello, M. D. Adams, M. Cargill, and A. G. Clark. 2005. Natural selection on proteincoding genes in the human genome. Nature 437:1153-1157.

Krey, G., H. Keller, A. Mahfoudi, J. Medin, K. Ozato, C. Dreyer, and W. Wahli. 1993. Xenopus peroxisome proliferator activated receptors: genomic organization, response element recognition, heterodimer formation with retinoid $\mathrm{X}$ receptor and activation by fatty acids. J. Steroid Biochem. Mol. Biol. 47:65-73.

Lee, C. H., P. Olson, A. Hevener, I. Mehl, L. W. Chong, J. M. Olefsky, F. J. Gonzalez, J. Ham, H. Kang, J. M. Peters, and R. M. Evans. 2006. PPARdelta regulates glucose metabolism and insulin sensitivity. Proc. Natl. Acad. Sci. USA. 103:3444-3449.

Livak, K. J. and T. D. Schmittgen. 2001. Analysis of relative gene expression data using real-time quantitative PCR and the 2(Delta Delta C(T)) Method. Methods 25:402-408.

Luquet, S., J. Lopez-Soriano, D. Holst, A. Fredenrich, J. Melki, M. Rassoulzadegan, and P. A. Grimaldi. 2003. Peroxisome proliferator-activated receptor delta controls muscle development and oxidative capability. FASEB J. 17:2299-2301.
Mahoney, D. J., G. Parise, S. Melov, A. Safdar, and M. A. Tarnopolsky. 2005. Analysis of global mRNA expression in human skeletal muscle during recovery from endurance exercise. FASEB J. 19:1498-1500.

Park, K. D., J. Park, J. Ko, B. C. Kim, H. S. Kim, K. Ahn, K. T. Do, H. Choi, H. M. Kim, S. Song, S. Lee, S. Jho, H. S. Kong, Y. M. Yang, B. H. Jhun, C. Kim, T. H. Kim, S. Hwang, J. Bhak, H. K. Lee, and B. W. Cho. 2012. Whole transcriptome analyses of six thoroughbred horses before and after exercise using RNA-Seq. BMC Genomics 13:473.

Saitou, N. and M. Nei. 1987. The neighbor-joining method: A new method for reconstructing phylogenetic trees. Mol. Biol. Evol. 4:406-425.

Tamura, K., D. Peterson, N. Peterson, G. Stecher, M. Nei, and S. Kumar. 2011. MEGA5: Molecular evolutionary genetics analysis using maximum likelihood, evolutionary distance, and maximum parsimony methods. Mol. Biol. Evol. 28:2731-2739.

Wahli, W., O. Braissant, and B. Desvergne. 1995. Peroxisome proliferator activated receptors: Transcriptional regulators of adipogenesis, lipid metabolism and more. Chem. Biol. 2:261266.

Wang, Y. X., C. L. Zhang, R. T. Yu, H. K. Cho, M. C. Nelson, C. R. Bayuga-Ocampo, J. Ham, H. Kang, and R. M. Evans. 2004. Regulation of muscle fiber type and running endurance by PPARdelta. PLoS Biol. 2(10):e294.

Zeng, L., Y. Geng, M. Tretiakova, X. Yu, P. Sicinski, and T. G. Kroll. 2008. Peroxisome proliferator-activated receptor-delta induces cell proliferation by a cyclin E1-dependent mechanism and is up-regulated in thyroid tumors. Cancer Res. 68:65786586. 